\title{
Desempenho Acadêmico e Percepção de Crianças sobre Estilos de Liderança de Professores
}

\author{
Pâmella Batista de Souza1', https://orcid.org/0000-0003-3832-7669
}

Ana Priscila Batista ${ }^{1}$, https://orcid.org/0000-0001-9849-3998

\section{Resumo}

Este estudo teve como objetivo verificar a relação entre o desempenho acadêmico de crianças e a percepção destas quanto aos estilos de liderança de seus professores. Participaram 119 alunos de $4^{\circ}$ e $5^{\circ}$ anos de escolas públicas do Ensino Fundamental, com idade entre 8 e 11 anos. Os alunos foram distribuídos, conforme suas notas, em três grupos: baixo, médio e alto desempenho escolar. Foi utilizado o Inventário de Estilos de Liderança de Professores para coleta de dados. Os resultados mostraram que, com relação aos grupos de desempenho escolar e os estilos de liderança de professores, não houve resultado significativo estaticamente $(p>0,05)$. No entanto, encontrou-se relação entre percepção de maior uso de controle coercitivo pelo professor no grupo de menor desempenho escolar quando comparado ao grupo de alto desempenho escolar, sendo essa diferença estatisticamente significativa $(p<0,05)$. Discute-se esta relação e aponta-se para a importância de práticas educativas mais positivas.

Palavras-chave: Liderança; professores; rendimento escolar.

\section{The Academic Performance and Child Perceptions of Teacher Leadership Styles}

\begin{abstract}
This study aimed to verify the relationship between the academic performance of children and their perception of the leadership styles of their teachers. There are119 students from 4th and 5th years of public elementary schools, aged between 8 and 1 who participated the study. The students were distributed according to their grades in three groups: low, medium and high school performance. The Teacher Leadership Styles Inventory was used for data collection. The results showed that, in relation to the school performance groups and the teacher leadership styles, there was no statistically significant result $(p>0.05)$. However, there was a relationship between the perception of greater use of coercive control by the teacher in the group of lower school performance when compared to the group with high school performance, this difference being statistically significant $(p<0.05)$. We discuss this relationship and point out the importance of more positive educational practices.
\end{abstract}

Keywords: Leadership; teachers; academic achievement.

\section{Desempeño Académico y Percepción de Niños sobre Estilos de Liderazgo de Profesores}

\section{Resumen}

En este estudio se tuvo por objetivo averiguar la relación entre el desempeño académico de niños y la percepción de ellos mismos cuanto a los estilos de liderazgo de sus profesores. Participaron 119 alumnos de $4^{\circ}$ y $5^{\circ}$ cursos de escuelas públicas de la Enseñanza Básica, con edad entre 8 y 11 años. Los alumnos fueron distribuidos, conforme sus notas, en tres grupos: bajo, medio y alto desempeño escolar. Se utilizó el Inventario de Estilos de Liderazgo de Profesores para recolecta de datos. Los resultados mostraron que, con relación a los grupos de desempeño escolar y los estilos de liderazgo de profesores, no hubo resultado significativo estadísticamente $(p>0,05)$. Sin embargo, se encontró relación entre percepción de mayor uso de control coercitivo por el profesor en el grupo de menor desempeño escolar cuando comparado al grupo de alto desempeño escolar, siendo esa diferencia estadísticamente significativa $(p<0,05)$. Se discute esta relación y se apunta para la importancia de prácticas educativas más positivas.

Palabras clave: Liderazgo; profesores; rendimiento escolar.

1 Universidade Estadual de Centro-Oeste, Departamento de Psicologia - Irati, PR, Brasil.

Psicologia Escolar e Educacional, SP. Volume 22, Número 1, Janeiro/Abril de 2018: 37-45. 


\section{Introdução}

A Educação é definida por Skinner como "o estabelecimento de comportamentos que serão vantajosos para o indivíduo e para outros em algum tempo futuro" (Skinner, $1953 / 1989$, p. 378), este processo educacional se dá através de "agências educacionais", (Skinner, 1953/1989, p. 378 ) sendo uma delas a escola. A escola é a instituição que oferece o conhecimento formal de valores da sociedade aos seus participantes, tendo como propósito aumentar o desenvolvimento cognitivo e social do indivíduo, o que inclui conhecimento, habilidades sociais e resolução de problemas, considerada a função socializadora da educação (Novak \& Pelaez, 2004).

A escola ganha destaque por se tratar de um dos principais contextos de desenvolvimento do indivíduo, uma vez que possibilita interação, aprendizagem e socialização, pois nela as crianças estabelecem suas primeiras relações sociais e criam repertórios de conhecimento e comportamento que repercutirão em suas vidas, conforme afirmado por Hamre e Pianta (2006) e Novak e Pelaez (2004). As crianças permanecem a maior parte do seu tempo nesse contexto quando não estão em casa (Davis-Kean \& Eccles, 2005), o que demonstra o quanto a instituição escolar é importante para o desenvolvimento infantil.

Um dos profissionais que adquire importância e responsabilidade frente ao processo educacional, principalmente no ambiente escolar, é o professor, profissional que está em contato direto com os alunos e que, portanto, é quem planeja e faz vigorar as contingências de ensino a partir das quais o aluno aprenderá (Skinner, 1968/1972). O professor tem também a responsabilidadede realizar o planejamento de procedimentos de educação e avaliação que possibilitem ao estudante um ensino apropriado (Pereira \& cols., 2004).

Nesse mesmo sentido, é possível compreender que em sala de aula os professores norteiam o comportamento do aluno a partir do conjunto de estratégias educativas que utilizam e assim constituem diferentes climas emocionais nesse espaço. Tal aspecto é nomeado Estilo de Liderança de Professores, que Batista e Weber (2015) definem como sendo "O conjunto de atitudes direcionadas aos alunos e que, tomadas em conjunto, criam um clima emocional no qual os comportamentos são expressos, moderando a efetividade de uma prática particular e alterando a receptividade da criança à relação de ensino-aprendizagem" (p. 28).

De acordo com Hamre e Pianta (2006) estas atitudes dos professores relacionam-se a crenças que estes possuem e que adquiriram ao longo da vida, a partir das contingências a que foram expostos. O estilo de liderança de professores pode ser avaliado a partir do cruzamento das dimensões Responsividade e Exigência, que podem somar-se, em alguma medida, ao Controle Coercitivo (Batista \& Weber, 2015).

A dimensão Responsividade diz respeito à qualidade da comunicação, do envolvimento, participação e afetividade que o professor dispensa aos alunos. Nessa dimensão há predomínio de contingências de reforçamento positivo e em sua presença é possível que os alunos se sintam respeitados, contentes, confiantes e em um ambiente visto como acolhedor com atividades que podem ser prazerosas. A Exigência, por sua vez, refere-se às atitudes do professor de supervisionar e monitorar o comportamento do aluno, criando expectativas sobre o desempenho deste, prezando pela disciplina consistente e impondo limites e regras. Já o Controle Coercitivo, forma comum usada para persuadir o comportamento de outra pessoa (Sidman, 1990), expressa-se na relação entre professor e aluno como o uso, por parte do professor, de determinados comportamentos como ameaças e punições inadequadas e assim, impor um clima negativo em sala de aula. Aqui, há a presença de contingências aversivas intensas e opressivas, sendo que os alunos podem sentir-se com medo e/ou raiva do professor (Batista \& Weber, 2015).

Autores clássicos como Skinner (1953/1989) e Sidman (1990) citam controle coercitivo e aversivo como sinônimos. No entanto, Batista e Weber (2015, p. 10) distinguem os dois e afirmam que o controle coercitivo é mais pertinente para se referir ao controle negativo que se dá de forma intensa, não justificável e opressiva, atendendo, especificamente na relação professor-aluno, muito mais ao professor do que ao aluno.

As três dimensões propostas pelo modelo de Estilos de Liderança de Professores possibilitam compreender as relações estabelecidas no contexto escolar, sobretudo, entre professor-aluno, e quando cruzadas as dimensões de responsividade e exigência geram quatro estilos, sendo eles: autoritativo, autoritário, permissivo e negligente, que podem somar-se em alguma medida ao controle coercitivo. Por serem distintos um do outro, os estilos propiciam uma interação diferente entre professor-aluno (Batista \& Weber, 2015). No estilo autoritativo, o professor apresenta equilíbrio entre responsividade e exigência. No autoritário, há o predomínio de uma exigência alta e baixa responsividade. No estilo permissivo os professores apresentam responsividade alta, porém, uma exigência baixa. No estilo negligente, há uma baixa responsividade e exigência (Batista \& Weber, 2015). Cada estilo pode influenciar de diferentes maneiras a relação que o professor estabelece com seu aluno, acarretando em consequências positivas ou negativas em diversos âmbitos da vida do estudante.

A relação entre professor e aluno é marcada pelo processo ensino-aprendizagem, que segundo Kubo e Botomé (2001, p. 123) «um nome para um complexo sistema de interações comportamentais entre professores e alunos». Hamre e Pianta (2006) descrevem que a relação estabelecida entre professor e aluno é perpassada por diversas questões como as características não só do professor, mas também do aluno e citam, de forma específica, características de cada um desses participantes. Sobre as dos professores, os autores assinalam que fatores como as crenças e percepções que os professores possuem sobre os alunos são relevantes e interferem nessa relação. Um exemplo disto é que quando o docente mantém uma expectativa alta em relação ao aluno, esse consegue atingir mais objetivos e apresenta melhor autoestima e competência. Kesner (2000) afirma que as percepçõesdos professores da relação com seus alunos 
pode estar relacionado às características da criança e do professor, tais como gênero e etnia.

As características dos estudantes vão desde o histórico de desenvolvimento, suas percepções e crenças, seus desempenhos acadêmicos e sociais, como interagem normalmente, além de questões como problema de comportamento e gênero (Hamre \& Pianta, 2006). Conforme Hamre e Pianta (2006), tanto o professor quanto o aluno trazem características de si mesmos para dentro de sala de aula e ali, causando impressões um no outro que acarretarão na forma como irão interagir entre si, além, é claro, das influências externas. Ainda, a relação entre alunos e professores muda conforme a criança avança nos anos escolares, pois a relação em cada ano é marcada por diferentes características, visto também a idade para a criança e o que lhe é esperado. No entanto, os autores salientam que a necessidade das relações positivas com os professores não diminui à medida que as crianças amadurecem.

Há, atualmente, no cenário nacional e internacional, um crescente número de pesquisas desenvolvidas a fim de compreender a interação estabelecida entre professor e aluno e também a repercussão dessa interação em diversos âmbitos da vida da criança, conforme exposto por Batista (2013). Como exemplo, o estudo desenvolvido por Walker (2008) destaca que as representações que as crianças possuem sobre seus professores podem influenciar em seu aprendizado escolar. Hamre e Pianta (2006) afirmam que a relação professor-aluno repercute no desenvolvimento global da criança, no convívio social com os colegas, além de despertar ou não um maior sentimento de segurança. Baker (2006) assinala que essa relação interfere na adaptação da criança na escola, e, portanto, na presença ou não de problemas de comportamento, além do sucesso ou insucesso escolar dessa criança e também sua confiança em si mesma.

Autores como Fumo (2009), Martini (2003) e Walker (2008) também afirmam que as estratégias educativas adotadas pelo professor em sala de aula podem interferir no desempenho acadêmico dos alunos. Nesse sentido, a relação que o aluno possui com o aprendizado e o conhecimento assume interferência da relação que este possui com seu professor. Fumo (2009) identificou os padrões comportamentais de crianças com baixo e alto desempenho escolar na relação com seus professores e afirmou que há diferenças entre esses dois grupos, tais como o repertório de habilidades sociais destes alunos. Martini (2003) identificou que professoras facilitadoras tendem a interagir mais com alunos com baixo desempenho acadêmico, enquanto as professoras que causam dificuldades interagem mais com alunos de alto desempenho acadêmico, atentando para a implicação das crenças dos professores sobre a aprendizagem dos estudantes. Assim, fica claro que a qualidade da interação entre docente e aluno pode interferir no desempenho acadêmico do estudante, pois a percepção que os alunos possuem sobre seus professores condiciona a interpretação deles de tudo aquilo que o professor diz e faz (Fumo, 2009).

Neste sentido, Hamre e Pianta (2006) apontam que é primordial investigar os efeitos da interação professor-aluno, pois isso pode ser um fator muito importante sobre o processo de aprendizado do aluno e reflete, possivelmente, no desempenho acadêmico deste.

Compreendendo, então, a importância da relação estabelecida entre professor-aluno pelo fato de interferir em diversos aspectos do desenvolvimento infantil, observa-se a importância de se verificar a relação entre estilos de liderança dos professores, por meio das dimensões analisadas, e o desempenho acadêmico dos alunos. Assim, o presente estudo buscou identificar os estilos de liderança de professores a partir da percepção dos alunos e verificar as relações com o desempenho acadêmico destes.

\section{Método}

\section{Participantes}

Participaram da pesquisa 119 alunos, de ambos os sexos, de $4^{\circ}$ ano e $5^{\circ}$ ano do Ensino Fundamental de três escolas públicas de um município do interior do Estado do Paraná. A idade variou entre 8 anos e 11 anos, sendo a média de 9,5 anos.

Na tabela 1 são apresentados os números referentes ao gênero, ano escolar e idade dos participantes em termos de frequência e na coluna abaixo de porcentagem.

Tabela 1. Frequência e porcentagem dos alunos quanto ao gênero, ano escolar e idade da amostra de participantes.

\begin{tabular}{lcccccccc}
\hline & \multicolumn{3}{c}{ Gênero } & \multicolumn{3}{c}{ Ano Escolar } & \multicolumn{3}{c}{ Idade } \\
\cline { 2 - 10 } & $\mathrm{F}$ & $\mathrm{M}$ & $4^{\circ}$ & $5^{\circ}$ & 8 & 9 & 10 & 11 \\
\hline Frequência & 55 & 64 & 37 & 82 & 7 & 49 & 58 & 5 \\
\hline Porcentagem & 46,2 & 53,8 & 31,1 & 68,9 & 5,88 & 41,18 & 48,74 & 4,20 \\
\hline
\end{tabular}

Fonte: Dados da pesquisa (adaptado pelas autoras). 


\section{Materiais e Instrumentos}

Inventário de Estilos de Liderança de Professores IELP (Batista \& Weber, 2015): O IELP busca identificar os Estilos de Liderança de Professores de alunos de $4^{\circ}$ e $5^{\circ}$ anos do Ensino Fundamental. Possui 56 itens referentes a descrição de situações e comportamentos do professor diante das quais os alunos devem responder sobre a frequência com que aparecem: "Nunca ou quase nunca", "Às vezes", "Sempre ou quase sempre", caracterizando-se uma escala Likert de 3 pontos com valores propostos para a correção sendo respectivamente 01, 02 e 03. Assim, o aluno avalia a frequência que o professor utiliza as práticas descritas em cada item e assinala a escala. A forma de correção se dá pela soma dos valores correspondentes às respostas aos itens de cada Escala (escore de cada escala). Dos 56 itens, 21 referem-se à escala Responsividade, 16 sobre Exigência e 19 itens sobre Controle Coercitivo. A partir do cruzamento destes itens, o IELP apresenta a classificação dos estilos de liderança de professores, que podem ser: Autoritativo, Autoritário, Permissivo ou Negligente, podendo ser somados em alguma medida ao Controle Coercitivo.

Medida de Desempenho Acadêmico por meio de Notas: As notas foram fornecidas pela coordenação pedagógica de cada escola e copiadas pelas pesquisadoras, sendo os alunos identificados apenas pelas iniciais do nome. A partir destas, os alunos foram distribuídos em três grupos em razão de seu rendimento nas disciplinas de língua portuguesa e matemática, sendo tal rendimento estabelecido a partir dos seguintes critérios: as notas das duas matérias, referente aos dois primeiros bimestres do ano letivo em que ocorreu a coleta de dados, foram somadas e divididas por quatro (duas disciplinas em dois bimestres cada), obtendo-se a média aritmética denominada "média escolar". A partir dos resultados dessas somas, os participantes foram agrupados de acordo com suas notas, em três categorias: "baixo", "médio" e "alto" desempenho acadêmico. A nota para pertencimento a estas determinadas classes foram: abaixo de 6,9, pertencimento ao grupo "Baixo Desempenho Acadêmico"; entre 7,0 e a nota 8,4 , pertencimento ao grupo "Médio Desempenho Acadêmico"; e entre 8,5 e 10,0, o pertencimento ao grupo "Alto Desempenho Acadêmico".

\section{Procedimentos de coleta de dados}

A coleta de dados foi realizada em três escolas públicas, sendo duas turmas em uma escola, duas em outra e quatro na terceira escola. A aplicação do instrumento ocorreu de forma coletiva no horário de aula e no próprio espaço de sala de aula, porém, com ausência dos professores regentes da turma. A duração média de cada uma das aplicações foi de vinte a trinta minutos. As crianças foram instruídas a responderem inicialmente às questões sobre seus dados sociodemográficos e posteriormente às questões referentes ao comportamento de seus professores. Então, as pesquisadoras leram em voz alta as instruções gerais para o preenchimento do instrumento. Após a certificação da compreensão a respeito da resolução das questões, bem como a resolução de dúvidas, foi dado início à aplicação do instrumento. No decorrer das aplicações as pesquisadoras permaneceram à disposição dos alunos, sendo que os que relataram dificuldades na leitura e/ou compreensão do instrumento tiveram auxílio individual para seu preenchimento.

\section{Procedimento de análise dos dados}

O IELP preenchido por cada participante foi corrigido individualmente. Na sequência foi realizada a soma do valor referente às respostas de cada participante aos itens de cada escala, obtidos, então, os escores brutos e o percentil correspondente, o que possibilitou a classificação recebida e o estilo de liderança do professor.

O índice final de cada estilo, juntamente com as notas escolares, que possibilitam o agrupamento dos alunos de acordo com diferentes desempenhos (baixo, médio e alto desempenho), foram computados no Software Statistical Package for the Social Sciences (SPSS), versão para Windows. Foi verificada a normalidade e utilizados os testes ANOVAe Tukey.

\section{Aspectos Éticos da Pesquisa}

O presente estudo foi submetido inicialmente ao Comitê de Ética em Pesquisa com Seres Humanos e Animais da Universidade Estadual do Centro-Oeste e obteve parecer favorável à sua realização, número 706.284.

\section{Resultados e Discussão}

Inicialmente é apresentada a porcentagem referente aos participantes pertencentes a cada grupo de desempenho escolar, apresentada na Figura 01, exposta a seguir.

Observa-se que há um maior número de crianças inseridas no grupo de Alto Desempenho Acadêmico ( $N=52)$, o que significa $44 \%$ da população total da pesquisa. $\mathrm{Na}$ sequência, 39\% dos estudantes estão no grupo de Médio Desempenho Acadêmico ( $N=47)$ e por fim, $17 \%$ estão no grupo de Baixo Desempenho Acadêmico ( $\mathrm{N}=20)$.

Para verificar a distribuição normal dos dados foi feita a inspeção visual da forma como os dados referentes às médias estão distribuídos no histograma. Assim, verificou-se que a frequência dos dados está distribuída em formato de um sino ou curva normal. Além disso, no teste Kolmogorov-Smirnov o valor-p foi maior que $0,05(p=0,166)$, o que também indica a distribuição normal dos dados. Considerando isso, optou-se por utilizar a análise estatística inferencial paramétrica na comparação entre os grupos. O teste ANOVA foi utilizado para verificar se existe diferença entre os três grupos (baixo, médio, alto desempenho) em relação aos escores obtidos em cada uma das dimensões do IELP. Conforme demonstrado abaixo: 


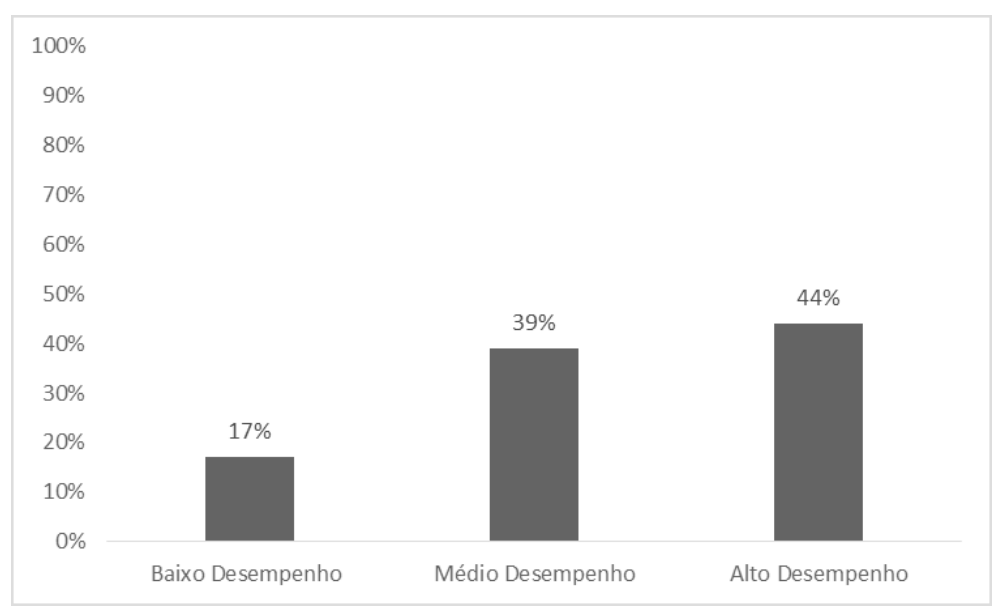

Figura 01. Porcentagem de participantes em cada grupo de desempenho escolar.

A partir dos dados apresentados na tabela 2 pode-se observar que há diferença estatisticamente significativa entre os grupos apenas na dimensão Controle Coercitivo. $(p<0,05)$. Diante disso, foi feito o teste Tukey para verificar a diferença entre os grupos e os dados são apresentados na tabela 3.

Observa-se uma diferença estatisticamente significativa $(p<0,05)$ entre os grupos baixo e alto desempenho acadêmico. Alunos do grupo com baixo desempenho percebem maior controle coercitivo de seus professores do que alunos com alto desempenho acadêmico.
Abordando, especificamente, o uso de práticas pautadas em Controle Coercitivo, Sidman (1990) afirma que a Coerção é um instrumento usado em nossa sociedade de forma bastante comum para persuadir o comportamento dos outros. No entanto, suas consequências são negativas. Ainda, conforme o autor, o controle coercitivo ocorre quando há a presença de comportamentos controlados por reforçamento negativo ou punição e pode gerar como consequência tanto comportamento de fuga como de esquiva.

Tabela 2. Distribuição de cada grupo de desempenho acadêmico com relação às dimensões Controle Coercitivo, Exigência e Responsividade.

\begin{tabular}{cccccc}
\hline Dimensões do IELP & Grupos & N & Média & $\begin{array}{c}\text { Desvio- } \\
\text { padrão }\end{array}$ & $\begin{array}{c}\text { ANOVA } \\
\text { (Sig.) }\end{array}$ \\
\hline \multirow{2}{*}{ Controle Coercitivo } & Baixo & 20 & 28,05 & 6,270 & \multirow{2}{*}{$\mathrm{P}<0,05$} \\
& Médio & 47 & 25,13 & 5,667 & \\
\cline { 2 - 5 } & Alto & 52 & 24,25 & 3,418 & \\
\hline \multirow{2}{*}{ Exigência } & Baixo & 20 & 41,10 & 6,223 & \multirow{2}{*}{$\mathrm{P}>0,05$} \\
& Médio & 47 & 40,77 & 5,230 & \\
\cline { 2 - 5 } & Alto & 52 & 41,02 & 5,027 & \\
\hline \multirow{2}{*}{ Responsividade } & Baixo & 20 & 7,920 & 7,920 & \multirow{2}{*}{$\mathrm{P}>0,05$} \\
& Médio & 47 & 6,981 & 6,981 & \\
\cline { 2 - 4 } & Alto & 52 & 5,71 & 5,781 & \\
\hline
\end{tabular}

Tabela 3. Teste Tukey para comparação entre os grupos na dimensão Controle Coercitivo.

\begin{tabular}{|c|c|c|}
\hline \multicolumn{2}{|c|}{ Grupos } & \multirow{2}{*}{$\begin{array}{c}\text { Sig } \\
0,072\end{array}$} \\
\hline Baixo & Médio & \\
\hline & Alto & 0,011 \\
\hline \multirow[t]{2}{*}{ Médio } & Baixo & 0,072 \\
\hline & Alto & 0,651 \\
\hline \multirow[t]{2}{*}{ Alto } & Baixo & 0,011 \\
\hline & Médio & 0,651 \\
\hline
\end{tabular}


Segundo Sidman (1990) o Controle Coercitivo é bastante utilizado em nossa sociedade. Sendo assim, uma das possibilidades de seu uso ser comum diz respeito ao fato deste trazer respostas de forma imediata (Skinner, 1953/1989). Segundo Batista e Weber (2015) e Zanotto (2004) um dos contextos em que é bastante utilizado é na área da educação e no ambiente escolar justamente por esse motivo: por suprimir um comportamento considerado como impróprio.

Ao adotar estratégias educativas baseadas em coerção, o professor estabelece um clima negativo em sala, com uso de ameaças e punições inadequadas. Tais contingências possibilitam, como consequência, o surgimento de sentimentos como medo, raiva e ansiedade, além de formas de contra controle expressas por meio de atraso nas aulas e criação de um ambiente hostil durante as atividades cotidianas (Batista \& Weber, 2015; Villani, 2002). Esses fatores podem interferir no resultado de baixo desempenho escolar do aluno, uma vez que o ensino está pautado em um clima negativo.

Comportamentos que estão sujeitos a punições tendem a se repetir assim que as contingências punitivas são removidas, ou seja, possuem curta duração (Skinner, 1953/1989). Zanotto (2000) evidencia que o professor, ao fazer uso, a longo prazo, de contingencias aversivas, produz um ambiente hostil que passa a marcar de forma profunda as atividades cotidianas em sala de aula, inserindo também emoções negativas como ansiedade e medo. Ainda no contexto escolar tais comportamentos podem ser expressos por meio de atrasos na aula por parte do aluno, diálogos em horários impróprios com os colegas, entre outros exemplos, conforme Viecili e Medeiros (2002, p. 235).

Uma das possibilidades de análise para a relação observada entre o uso de práticas coercitivas por parte dos professores e o baixo desempenho dos alunos, conforme os dados estatísticos, é que alunos com diferentes desempenhos acadêmicos comportam-se de forma diversa. Segundo Viecili e Medeiros, (2002), os professores fazem uso de coerção e estimulação positiva diferenciada entre alunos com desempenhos acadêmicos diferentes, pois alunos com altos desempenhos acadêmicos tendem a serem mais ativos e a participar mais das atividades escolares, enquanto os alunos com baixo desempenho acadêmico comportam-se muitas vezes indiferentes às atividades passadas em sala. Ou seja, estudantes com diferentes desempenhos acadêmicos comportam-se de forma diferente e, portanto, os professores podem fazer uso de coerção e estimulação positiva diferentemente com os grupos, punindo mais alunos com baixo desempenho e reforçando de forma positiva os comportamentos de alunos com alto desempenho escolar. Atrela-se a essa questão o fato de que muitas vezes a atuação do professor permanece sob dependência das ações inadequadas dos estudantes, do que sob os comportamentos considerados positivos. Tal ponto explicaria o possível uso de práticas coercitivas direcionado a alunos com baixo desempenho escolar. Além disto, o aluno tende também a aprender cada vez menos e a longo prazo que o ambiente coercitivo pode ser marcado por emoções negativas (Zanotto, 2000). Assim, situações que se utilizam de coerção não favorecem o aprendizado e muito menos um clima ameno em sala de aula.

Walker (2008) afirma que devido à influência das atitudes dos professores com seus alunos, é importante que aqueles possuam um controle firme, mas também repleto de ações e diálogos que incentivem a autonomia e a responsividade dos alunos. Assim, o ambiente de aprendizado torna-se, segundo o autor, efetivo. Batista e Weber (2015) afirmam que outros itens importantes para essa relação são a exigência a responsividade, que auxiliam na criação de um clima cordial em sala de aula, com atitudes positivas dos professores direcionadas aos seus alunos. Para Walker (2008) também o apoio afetivo dispensado em sala de aula pelo professor aumenta a influência positiva sob os alunos, além do incentivo à autonomia.

A relação estabelecida em sala de aula sofre a interferência do conjunto de estratégias educativas que o professor utiliza, que estabelece diferentes climas emocionais em sala de aula, chamado Estilo de Liderança de Professor, como anteriormente mencionado. No presente trabalho, foram analisados os dados referentes à porcentagem identificada de cada estilo de liderança de professores resultante das respostas dos alunos, conforme pode ser observado na Figura 2.

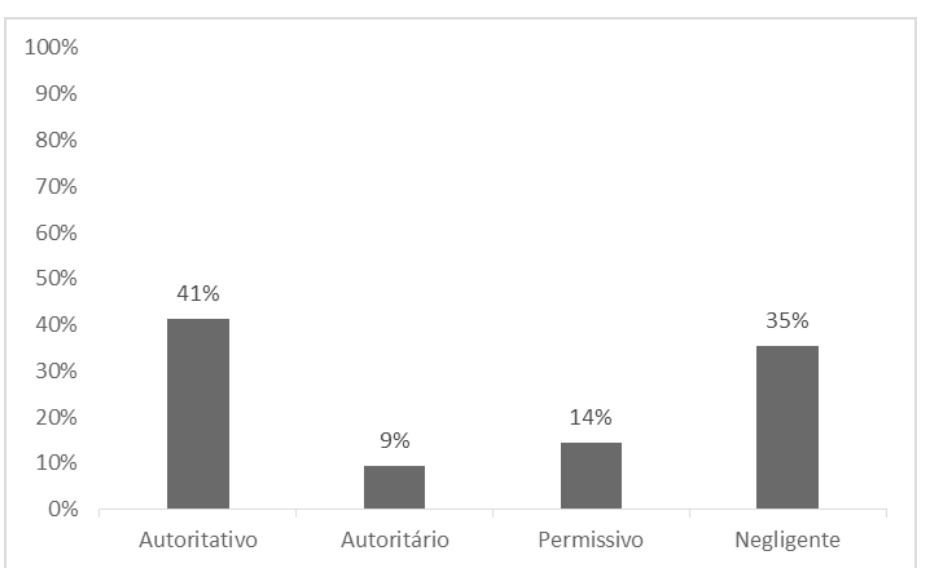

Figura 2. Porcentagem de Estilo de liderança dos professores conforme resposta das crianças. 


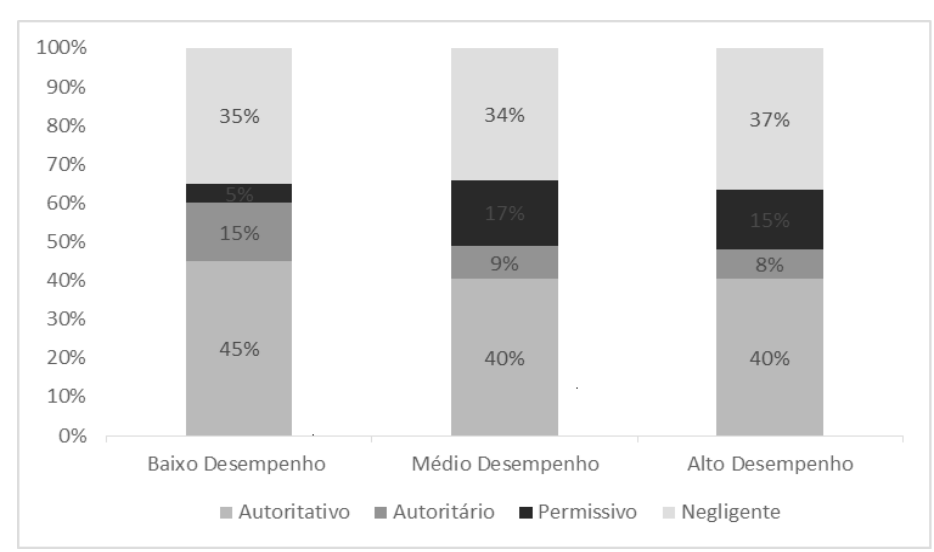

Figura 3. Distribuição em porcentagem de cada estilo de liderança de professor em cada grupo de desempenho acadêmico.

Pode-se perceber que o estilo mais evidente, de forma geral, é o autoritativo, sendo expresso por $41 \%(\mathrm{~N}=49)$ das crianças, seguido pelo negligente $(35 \%, \mathrm{~N}=42)$ e do permissivo $(14 \%, \mathrm{~N}=17)$. O estilo autoritário aparece com uma frequência de $9 \%(\mathrm{~N}=11)$. Cabe ressaltar que a análise realizada é com relação aos estilos de liderança de forma geral, não diferenciando-os quanto aos tipos, conforme consta em Batista e Weber (2015).

A Figura 3 representa a porcentagem de identificação de cada estilo de liderança de professores em cada grupo de desempenho escolar.

Destaca-se que o estilo Autoritativo é o que prevalece em todos os grupos, tendo uma prevalência de 40 a $45 \%$, seguido do Negligente, que oscilou em uma frequência de 34 a $37 \%$, tendo uma alteração de um grupo para outro de apenas $3 \%$. Os estilos Autoritário e Permissivo foram os que tiveram uma maior variabilidade entre os grupos, de forma que nos grupos de Médio e Alto Desempenho, o estilo permissivo foi o terceiro com maior porcentagem, $15 \%$ e $17 \%$ respectivamente, e o estilo autoritário foi o que apresentou menor frequência, oscilando entre $9 \%$ e $8 \%$ também respectivamente. Já no grupo de Baixo Desempenho, a porcentagem do estilo autoritário $(15 \%)$ foi superior à do negligente $(5 \%)$.

O estilo Autoritário obteve maior diferença de porcentagem entre os grupos. Este estilo foi identificado por $15 \%$ das crianças do grupo de baixo desempenho escolar, enquanto nos grupos de médio e alto desempenho a significância foi de $9 \%$ e $8 \%$, respectivamente.

Um dado importante é que o estilo Autoritário é a combinação de baixa responsividade e alta exigência. Professores vistos sob esse estilo não apresentam afetividade em relação aos estudantes, valorizam a autoridade, se abstém às demandas dos alunos e buscam, acima de tudo, a obediência por parte das crianças. Dessa forma, os alunos não têm suas opiniões consideradas. Nesse estilo, predominam as contingências de reforçamento negativo e punição. Aqui, as contingências aversivas são distintas das da dimensão controle coercitivo, pois relacionam-se às regras e há também contingências positivas, porém, apenas quando o aluno seguiu uma regra determinada. Já na dimensão Controle Coercitivo, o que ocorre é a presença de contingências de reforço negativo (fuga e esquiva) e de punição (positiva e negativa) de forma muito intensa, opressiva, não justificável, de forma independente de uma regra estabelecida, ou mesmo quando as consequências aversivas são muito intensas, não condizentes com as regras estabelecidas" (Batista \& Weber, 2015).

$\mathrm{O}$ estilo com maiores benefícios à relação professor-aluno e à diversos aspectos da vida do estudante é o Autoritativo, com presença equilibrada de responsividade e exigência. A percepção dos alunos de seus professores apresentando tal estilo foi predominante entre os grupos.

Ao analisar visualmente os dados obtidos sobre a diferença de percepção dos estilos de liderança de professores entre os grupos de desempenho acadêmico, foi possível notar uma relação entre o grupo de baixo desempenho acadêmico e os estilos autoritário e permissivo, pois enquanto nos grupos médios e altos desempenho a média de alunos que viam seus professores como autoritários e permissivos variavam entre $7-8 \%$ e $15-17 \%$ respectivamente, os de baixo desempenho assinalavam tais perfis como $15 \%$ e $5 \%$ também respectivamente.

No entanto, ao analisar estatisticamente, por meio do teste Qui ${ }^{2}$, a diferença de percepção dos estilos de liderança de professores entre os grupos de desempenho acadêmico, o resultado não foi estatisticamente significativo $(p>0,05)$.

\section{Considerações Finais}

O objetivo deste estudo foi verificar a relação entre os desempenhos acadêmicos de crianças do Ensino Fundamental e a percepção delas quanto aos estilos de liderança de seus professores. Os dados demonstram que alunos com baixo desempenho escolar percebem maior utilização de 
estratégias educativas coercitivas de seus professores do que alunos com médio e alto desempenho.

Por outro lado, a presente pesquisa apresentou algumas limitações, entre as quais destaca-se que foi utilizada a nota escolar em um continuum como parâmetro, sendo que os extremos também poderiam ser considerados. Possibilidades de novas pesquisas derivadas do presente estudo podem envolver metodologias distintas, como a possibilidade do uso de observação direta do comportamento para além do uso de um instrumento de autorrelato, tal como o utilizado na pesquisa (IELP). Também sugere-se o uso de instrumentos estruturados para avaliar o desempenho escolar. Além disso, considera-se importante investigar a concepção dos professores sobre sua relação com alunos que possuam diferentes desempenhos acadêmicos.

A partir dos resultados obtidos, aponta-se para a necessidade de conceber estratégias que utilizem o reforço positivo para o ensino de comportamentos almejados, destinados, principalmente, a alunos com "baixo" desempenho escolar. Nesse sentido, é primordial a substituição dessa prática ainda comum nas escolas, ou seja, pela troca de Controle Coercitivo pelo Controle Positivo para produção dos comportamentos desejáveis do aluno, como garantir que as tarefas dadas aos alunos sejam compatíveis com sua apreensão do conhecimento, além de reforçar ao máximo os comportamentos adequados dos estudantes (Pereira \& cols., 2004). Já Zanotto (2000) afirma que muitas vezes os professores se utilizam dessa prática sem conhecer os seus efeitos e dessa forma é necessário apresentar a eles outros meios, mais saudáveis, para se atingir o mesmo fim: a aprendizagem dos alunos.

Os resultados obtidos neste trabalho assinalam a possibilidade e a necessidade de se trabalhar com professores, de forma a apresentar-Ihes alternativas, como por exemplo, o uso de reforçadores positivos, compreendendo o grau de apreensão do aluno e suas individualidades, entre outras possibilidades (Zanotto, 2004).

Conforme Zanotto (2000, p. 124) "compete ao professor planejar e executar procedimentos de ensino, sob a forma de contingências de reforçamento, que possibilitem ao aluno uma aprendizagem produtiva e prazerosa, sem os inconvenientes das práticas aversivas". É importante que os professores se utilizem de práticas que substituam os comportamentos inadequados e não simplesmente tragam o desaparecimento temporário de tais comportamentos, como o que acontece em contingências punição ou reforço negativo, pois, como apontam Viecili e Medeiros (2002), quando a aprendizagem é promovida por meio de uso de consequências reforçadoras e positivas, há uma maior probabilidade de o aluno ampliar seus conhecimentos, além de obter uma relação professor-aluno mais satisfatória. Tal procedimento traz benefícios para o aluno, que aprende sem estar sob contingências aversivas e também para o professor, que ao exercer seu papel obtêm êxito nele.

\section{Referências}

Baker, J. A. (2006). Contributions of teacher-child relationships to positive school adjustment during elementary school. Journal of School Psychology, 44, 211- 229.

Batista, A.P. (2013). Construção e análise de parâmetros psicométricos do Inventário de Estilos de Liderança de Professores. 181 p. Tese (Doutorado em Educação) - Universidade Federal do Paraná, Curitiba.

Batista, A.P., \& Weber, L. (2015). Professores e estilos de liderança: manual para identificá-los e modelo teórico para compreendê-los. Curitiba: Juruá. 86 p.

Cadima, J., Leal, T., \& Peixoto, C. (2012). Observação das Interacções educador-criança: Escala de interacção do prestador de cuidados. Análise Psicológica, 30(4), 373-386. Recuperado: 25 abr. de 2017. Disponível: http://www.scielo.mec.pt/scielo.php?script=sci_ arttext\&pid=S0870-82312012000300002\&lng=pt\&tlng=pt.

Davis-Kean, P.E. \& Eccles, J. S. (2005).Influences and challenges to better parent-school collaborations. Em: Patrikakou, E. M., R. P., Weissberg, S. Redding, \& Walberg, H. J. (Orgs.) School-family partnerships for chidren's success. New York: Teacher College Press.

Fumo, V. M. S. (2009). Habilidades sociais acadêmicas de crianças com baixo e alto Desempenho acadêmico na interação com o professor. Dissertação (Mestrado em Educação) - Universidade Federal de São Carlos, São Carlos, SP.

Hamre, B.K. \& Pianta, R.C (2006). Student-teacher relationships; Schools. Em: Bear, G. G. \& Minke, K. M. (Eds.), Children's Needs II: development, prevention and intervention. Bethesda, MD: National Association of School Psychologists.

Kesner, J. E. (2000). Teacher characteristics and the quality of childteacher relationships. Journal of School Psychology, 28(2), 133149.

Kubo, O. \& Botomé, S. P. (2001). Ensino-Aprendizagem: uma interação entre dois processos comportamentais. Interação, Curitiba, 5, 123-132.

Martini, M. L. (2003). Variáveis psicológicas de professores e alunos, ações interativas e Desempenho acadêmico: investigando possíveis relações. Tese (Doutorado em Psicologia) - Universidade de São Paulo, Ribeirão Preto, SP.

Novak, G. \& Peláez, M. (2004). Schools. Em: Novak, G. \&Peláez, M. (2004). Child and adolescent development: a behavioral systems approach. Califórnia: Sage Publications.

O'Connor, E. (2010). Teacher-child relationships as dynamic systems. Journal of School Psychology, 48, 187-218. 
Pereira, M.E.M., Marinotti, M., \& Luna, S.V. (2004). O Compromisso do professor com a aprendizagem do aluno: contribuições da Análise do Comportamento. Em: Hubner, M.M.C. \& Marinotti, M (Orgs.), Análise do Comportamento para a Educação: Contribuições Recentes. Santo André, SP: ESETec Editores Associados.

Sidman, M. (1990). Coerção e suas implicações. Campinas, SP: Livro Pleno, $301 \mathrm{p}$.

Skinner, B. F. (1989). Ciência e Comportamento Humano (7a ed.). São Paulo: Martins Fontes. (Trabalho original publicado em 1953).

Skinner, B. F. (1972). Tecnologia do ensino. São Paulo: Ed. Herder, Ed. USP. (Trabalho original publicado em 1968).

Skinner, B. F. (1991). Questões recentes na Análise do Comportamento. 5 Ed. Rio de Janeiro: Papirus.

Viecili, J. \& Medeiros, J.G. (2002). A Coerção e suas implicações na relação professor-aluno. Revista Psico-USF, v.7, n.2, p. 229-238, Jul./Dez.
Villani, M. C. S. (2002). Alguns aspectos da abordagem skinneriana sobre educação. Em: Teixeira, A. M. S. (Org.) Ciência do Comportamento- conhecer e avançar (v. 2., pp. 51-55). Santo André: ESETec.

Walker, J. M. T. (2008). Looking at teacher practices through the lens of parenting style. The Journal of Experimental Education, 76(2), 218-240.

Zanotto, M. L. B. (2000). Formação de professores: a contribuição da análise de comportamento. São Paulo: EDUC, 183p.

Zanotto, M.L.B. (2004). Subsídios da análise do comportamento para a formação de professores. Em: Hubner, M.M.C. \& Marinotti, M. (Orgs.), Análise do comportamento para a educação: contribuições recentes. Santo André: ESETec.

\section{Sobre as autoras}

Pâmella Batista de Souza (pampampam.ella@hotmail.com)

Acadêmica de Psicologia. Universidade Estadual do Centro-Oeste - Irati - PR

https://orcid.org/0000-0003-3832-7669

Ana Priscila Batista (anapribatista@yahoo.com.br)

Doutora em Educação Universidade Estadual de Centro-Oeste - Irati - PR

https://orcid.org/0000-0001-9849-3998

$(\mathrm{cc}) \mathbf{E Y}$

License information: This is an open-access article distributed under the terms of the License (type CC-BY), which permits unrestricted use, distribution and reproduction in any medium, provided the original article is properly cited. 
